\title{
Clinical significance of mTOR, ZEB1, ROCK1 expression in lung tissues of pulmonary fibrosis patients
}

\author{
Jong Sun Park', Hyo Jin Park², Young Sik Park³, Sang-Min Lee³, Jae-Joon Yim³, Chul-Gyu Yoo ${ }^{3}$, Sung Koo Han ${ }^{3}$
} and Young Whan $\mathrm{Kim}^{3 *}$

\begin{abstract}
Background: Idiopathic pulmonary fibrosis (IPF) is a fatal lung disease of unknown causes. Three proteins (mammalian target of rapamycin, mTOR; zinc finger E-box-binding homeobox 1, ZEB1; Rho-associated, coiled-coil containing protein kinase 1, ROCK1) may be related to pulmonary fibrosis. However, they have not been assessed in human pulmonary fibrosis. We assessed the clinical significance of mTOR, ZEB1, and ROCK1 expression in human pulmonary fibrosis of usual interstitial pneumonia (UIP) pattern.

Methods: The mTOR, ZEB1, and ROCK1 expression was evaluated by immunohistochemical staining of 30 surgical lung biopsy tissues from 26 IPF and 4 UIP pattern connective tissue disease related interstitial lung disease (CTD-ILD) patients. The expression scores correlated with the clinical features.

Results: The mTOR, ZEB1 and ROCK1 mainly expressed in alveolar epithelial cells of UIP lungs. The histological fibrosis scores and lung function decline in the strong mTOR expression group were higher than those in the weak and intermediate expression group. Patients with positive ZEB1 expression had higher fibrosis scores and greater decline in carbon monoxide diffusion capacity $\left(\mathrm{DL}_{\mathrm{CO}}\right)$ than patients with negative ZEB1 expression. Patients with positive mTOR or ZEB1 expression had poorer prognosis than that of patients with negative mTOR or ZEB1 expression, although it was not statistically significant. ROCK1 was not associated with the studied clinicopathological features.

Conclusions: The mTOR and ZEB1 expression in pulmonary fibrosis patients significantly correlated with the fibrosis score and lung function decline, indicating that it may be related to the prognosis of pulmonary fibrosis. Further studies involving large numbers of homogeneous IPF patients are warranted.
\end{abstract}

Keywords: Pulmonary fibrosis, Immunohistochemical analysis, Usual interstitial pneumonia, mTOR, ZEB1, ROCK1, Survival

\section{Background}

Idiopathic pulmonary fibrosis (IPF) is a chronic, progressive, irreversible, lethal lung disease of unknown cause, histologically defined as usual interstitial pneumonia (UIP) [1]. The initiating injury and subsequent pathways for IPF have not been elucidated, but the disease is considered to be an epithelial fibrotic disorder. It is characterized by epithelial injury followed by aberrant wound healing with excessive fibrosis and minimal inflammation. In these

\footnotetext{
* Correspondence: ywkim@snu.ac.kr

${ }^{3}$ Division of Pulmonary and Critical Care Medicine, Department of Internal Medicine, Seoul National University College of Medicine, Seoul National University Hospital, Medicine, 101 Daehak-ro, Jongno-gu, Seoul 110-744, Korea

Full list of author information is available at the end of the article
}

processes, growth factors, cytokines, and other mediators are released, followed by excessive extracellular matrix deposit and abnormal mesenchymal cell proliferation in the lungs. However, little is known about the detailed pathogenesis of pulmonary fibrosis development.

Mammalian target of rapamycin (mTOR) complex is a highly conserved intracellular serine/threonine kinase and a major downstream component of phosphatidyl inositol 3kinase (PI3K). The mTOR regulate translation of specific mRNAs and protein synthesis involved in cell cycle regulation and has been shown to influence tissue fibrosis [2]. A previous study demonstrated that the initiation and progression of pulmonary fibrosis was prevented by the administration of rapamycin, an mTOR inhibitor, to a transgenic 
mouse with pulmonary fibrosis induced by lung-specific expression of the EGFR ligand, transforming growth factor (TGF)- $\alpha$ [3]. In addition, a previously published case study reported that rapamycin was successfully used to treat a patient with IPF [4].

Zinc finger E-box-binding homeobox 1 (ZEB1) protein is a key transcription factor that acts downstream of TGF- $\beta$ which has been implicated in the epithelial-mesenchymal transition (EMT) [5]. The EMT is thought to contribute to development of pulmonary fibrosis. Furthermore, there is a report that ZEB1 gene is overexpressed in the lung tissues of interstitial lung disease patients [6].

Rho-associated, coiled-coil containing protein kinase 1 (ROCK1) is a serine/threonine kinase and a downstream effector of Rho. It controls cell adhesion and cell motility via actin-cytoskeleton reorganization and actin-myosin filament bundles regulation. A previous study demonstrated that RhoA/ROCK inhibitor attenuated pulmonary fibrosis in animal models [7].

Therefore, it is hypothesized that mTOR pathway, ZEB1, and ROCK1 may play a role in the pathogenesis of pulmonary fibrosis. However, these proteins have not been assessed in human pulmonary fibrosis. This study was performed to identify the clinical significance of mTOR, ZEB1, and ROCK1 expression in the lung tissues of idiopathic pulmonary fibrosis and UIP pattern connective tissue disease related interstitial lung disease (CTD-ILD) patients.

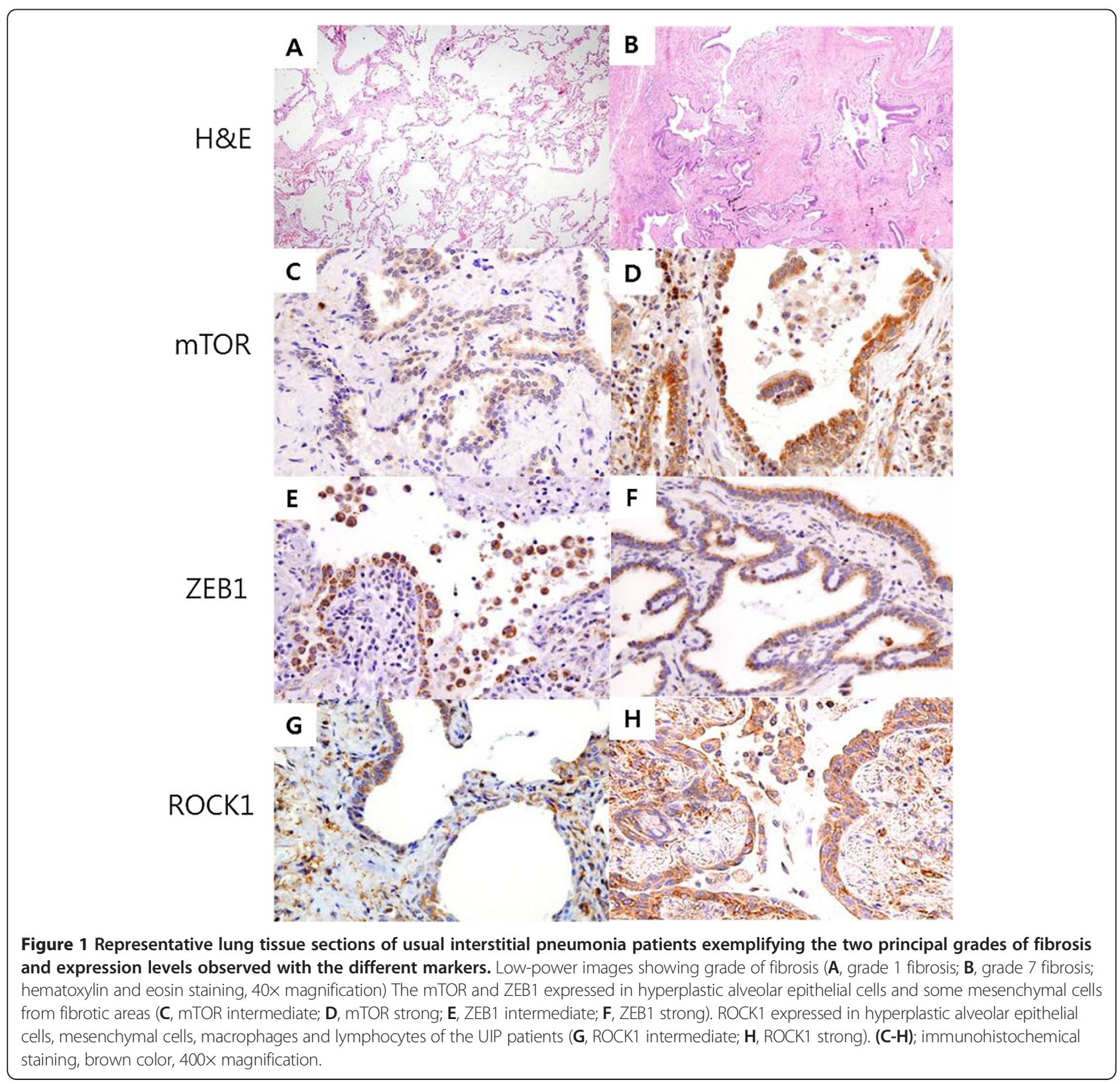




\section{Methods}

\section{Study population}

We enrolled 30 pulmonary fibrosis patients from January 2005 to May 2010 at Seoul National University Hospital. The study included patients who underwent surgical lung biopsy, and were histologically diagnosed with usual interstitial pneumonia (UIP). The pathological diagnosis was undertaken using previously established criteria, and clinical diagnosis was judged according to the international guidelines [8]. Two normal lung tissues were obtained from certified tissue bank to compare with UIP lungs. The

\section{Table 1 Characterstics of the study patients}

\begin{tabular}{|c|c|}
\hline Variables & $N=30$ \\
\hline Age, years, median (range) & $57(38-74)$ \\
\hline Male sex & $14(46.7)$ \\
\hline \multicolumn{2}{|l|}{ Smoking } \\
\hline Never smoker & $19(63.3)$ \\
\hline Former smoker & $7(23.3)$ \\
\hline Current smoker & $4(13.3)$ \\
\hline Follow up, months & $40(5-74)$ \\
\hline Connective tissue disease & $4(13.3)$ \\
\hline \multicolumn{2}{|l|}{ Arterial blood gas analysis $(n=28)$} \\
\hline $\mathrm{pH}$ & $7.41 \pm 0.0$ \\
\hline $\mathrm{PaO}_{2}, \mathrm{mmHg}$ & $92.0 \pm 16.0$ \\
\hline $\mathrm{PaCO}_{2}, \mathrm{mmHg}$ & $40.2 \pm 4.0$ \\
\hline Saturation, \% & $96.7 \pm 1.7$ \\
\hline \multicolumn{2}{|l|}{ White blood cell count } \\
\hline Neutrophil, /mm3 & $4003 \pm 127$ \\
\hline Lymphocyte, /mm3 & $2327 \pm 876$ \\
\hline \multicolumn{2}{|l|}{ Bronchoalveolar lavage $(n=15)$} \\
\hline Alveolar macrophage, \% & $46.1 \pm 21.1$ \\
\hline Neutrophil, \% & $23.0 \pm 22.2$ \\
\hline Lymphocyte, \% & $17.5 \pm 9.9$ \\
\hline \multicolumn{2}{|l|}{ Pulmonary function test } \\
\hline FVC, \% & $75.3 \pm 12.9$ \\
\hline $\mathrm{FEV}_{1}, \%$ & $86.9 \pm 13.5$ \\
\hline $\mathrm{DL} \mathrm{CO}_{\mathrm{C}} \%$ & $65.0 \pm 25.2$ \\
\hline \multicolumn{2}{|l|}{ Radiologic features } \\
\hline Ground glass opacities & $20(66.7)$ \\
\hline Reticular density & $10(33.3)$ \\
\hline Consolidation & $3(10.0)$ \\
\hline Traction bronchiectasis & $1(3.3)$ \\
\hline Honeycombing & $11(36.7)$ \\
\hline Steroids or immunosuppressive treatment & $16(53.3)$ \\
\hline Survivors & $24(80.0)$ \\
\hline
\end{tabular}

Definition of abbreviations: FVC $=$ forced vital capacity, $\mathrm{FEV}_{1}=$ forced expiratory volume in $1 \mathrm{~s}, \mathrm{DL}_{\mathrm{CO}}=$ carbon monoxide diffusion capacity

Data are presented as mean \pm SD or numbers (\%). demographic characteristics, pulmonary function, and chest computed tomography (CT) scan images of the study patients were reviewed. The survival data of the patients were obtained from the Ministry of Public Administration and Security. A part of the patient data was reported in a previous study [9]. This study was approved by the Institutional Review Board of the Seoul National University Hospital (H-1105-099-363).

\section{Immunohistochemical staining}

The expression of mTOR, ZEB1, and ROCK1 was evaluated by immunohistochemical staining of formalin-fixed and paraffin-embedded lung tissue sections, which were cut to a thickness of $4 \mu \mathrm{m}$. After deparaffinization in xylene and rehydration using graded alcohol to water, these slides were soaked in Target Retrieval Solution (Dako, Carpenteria, CA, USA), and then placed in a water bath at $97^{\circ} \mathrm{C}$ for $20 \mathrm{~min}$ to enable antigen retrieval. The sections were then immersed for $5 \mathrm{~min}$ in distilled water containing 3\% hydrogen peroxidase to block endogenous peroxidase activity. The sections were incubated for $30 \mathrm{~min}$ with primary antibodies for mTOR, ZEB1, and ROCK1 diluted 1:200, 1:100 and 1:50, respectively. The primary rabbit monoclonal mTOR and ROCK1 antibodies were purchased from Abcam (Cambridge, MA, USA). The primary goat polyclonal ZEB1 antibody was obtained from Santa Cruz Biotechnology (Santa Cruz, CA, USA). The Dako EnVision ${ }^{+}$

Table 2 Comparisons of clinical characteristics between idiopathic pulmonary fibrosis and connective tissue disease related interstitial lung disease of histologic usual interstitial pneumonia pattern

\begin{tabular}{lccc}
\hline & $\begin{array}{c}\text { IPF } \\
(\mathbf{n}=\mathbf{2 6})\end{array}$ & $\begin{array}{c}\text { CTD-ILD } \\
\mathbf{( n = 4 )}\end{array}$ & p value \\
\hline Age, years, median (range) & $62(38-74)$ & $52(48-55)$ & 0.139 \\
Male sex & $14(53.8)$ & 0 & 0.066 \\
Ever smoker & $11(42.3)$ & 0 & 0.141 \\
Pulmonary function test & & & \\
$\quad$ FVC, \% & $73.4 \pm 15.6$ & $78.0 \pm 15.9$ & 0.746 \\
$\quad$ FEV, \% & $85.4 \pm 16.3$ & $85.0 \pm 17.9$ & 0.837 \\
$\quad$ DL & $62.8 \pm 28.8$ & $65.7 \pm 22.2$ & 0.825 \\
Histologic fibrosis score & $12.9 \pm 8.0$ & $8.6 \pm 12.9$ & 0.220 \\
Radiologic honeycombing score & $2.1 \pm 1.9$ & $1.5 \pm 1.9$ & 0.791 \\
mTOR expression score & $4.4 \pm 2.8$ & $2.7 \pm 4.2$ & 0.245 \\
ZEB1 expression score & $3.2 \pm 2.6$ & $2.5 \pm 3.0$ & 0.576 \\
ROCK1 expression score & $3.4 \pm 2.9$ & $1.7 \pm 1.7$ & 0.359 \\
Steroids or immunosuppressive & $12(46.2)$ & $4(100)$ & 0.089 \\
treatment & & & \\
\hline Definition of abbreviations: IPF & & & \\
\hline
\end{tabular}

Definition of abbreviations: IPF = idiopathic pulmonary fibrosis, CTD-ILD = connective tissue disease related interstitial lung disease, $\mathrm{FVC}=$ forced vital capacity, $\mathrm{FEV}_{1}=$ forced expiratory volume in $1 \mathrm{~s}, \mathrm{DL}_{\mathrm{CO}}=$ carbon monoxide diffusion capacity.

Data are presented as mean \pm SD or numbers (\%). 
System that contains a horseradish peroxidase-labeled polymer was used along with $\mathrm{LSAB}^{\circ} 2$ (Dako, Carpenteria, CA, USA), a streptavidin-peroxidase conjugate that serves as the secondary antibody. Routinely processed tissue sections of prostate cancer, breast cancer, and thyroid cancer were used as positive staining controls for mTOR, ZEB1, and ROCK1 staining, respectively. Staining without the primary antibody was also performed to verify staining specificity.

\section{Histologic analysis}

Two pathologists reviewed the histology slides independently and without access to the clinical data. The fibrosis score was analyzed using the hematoxylin-and-eosinstained lung section slides. The extent of fibrotic lesions was scored as 0 (0-10\%), 1 (10-25\%), 2 (25-50\%), 3 (50-75\%), or 4 (75-100\%). The severity of fibrosis was scored from 0 (normal lung) to 8 (total fibrosis) by determining the average of 10 distinct microscopic fields at $200 \times$ magnification in accordance with the Ashcroft scoring system (Figure 1A,B) [10]. Finally, fibrosis scores were calculated by multiplication of the extent of fibrotic lesions to Ashcroft scores. The expression of mTOR, ZEB1, and ROCK1 was scored using both the intensity of staining and the percentage of positively stained alveolar epithelial cells. The total expression score was calculated by multiplying intensity score ( 0 , negative; 1 , weak; 2 , moderate; 3 , strong) to the score of the positively stained cells $(0,<10 \% ; 1,10$ $49 \%$; $2,50-75 \% ; 3,>75 \%)$. We randomly selected 10 microscopic fields under $100 \times$ magnification. Each field was individually assessed and the expression score was determined by obtaining the mean score of all the fields. Finally, the expression level was graded as negative (0), intermediate $(1-3)$, or strong $(\geq 4)$ based on the total expression score (Figure $1 \mathrm{C}-\mathrm{H})$.

\section{Radiological analysis}

Honeycombing on the chest CT scan images was defined as air-filled cysts with thick-walled, between the sizes of several millimeters to several centimeters in diameter. A previously published method [11] was used to assess the honeycombing score. Briefly, the whole lung was divided into 6 lobes (right upper, right middle, right lower, left upper, lingular division, and left lower lobe), and the extent of the honeycombing lesion was assessed as 0 (absent), 1 $(0-25 \%), 2(25-50 \%), 3(50-75 \%)$, or $4(<75 \%)$ in each lobe. The honeycombing score was the final sum of all 6 lobes.

\section{Statistical analysis}

The differences in patients' characteristics, on the basis of the expression of mTOR, ZEB1, and ROCK1, were

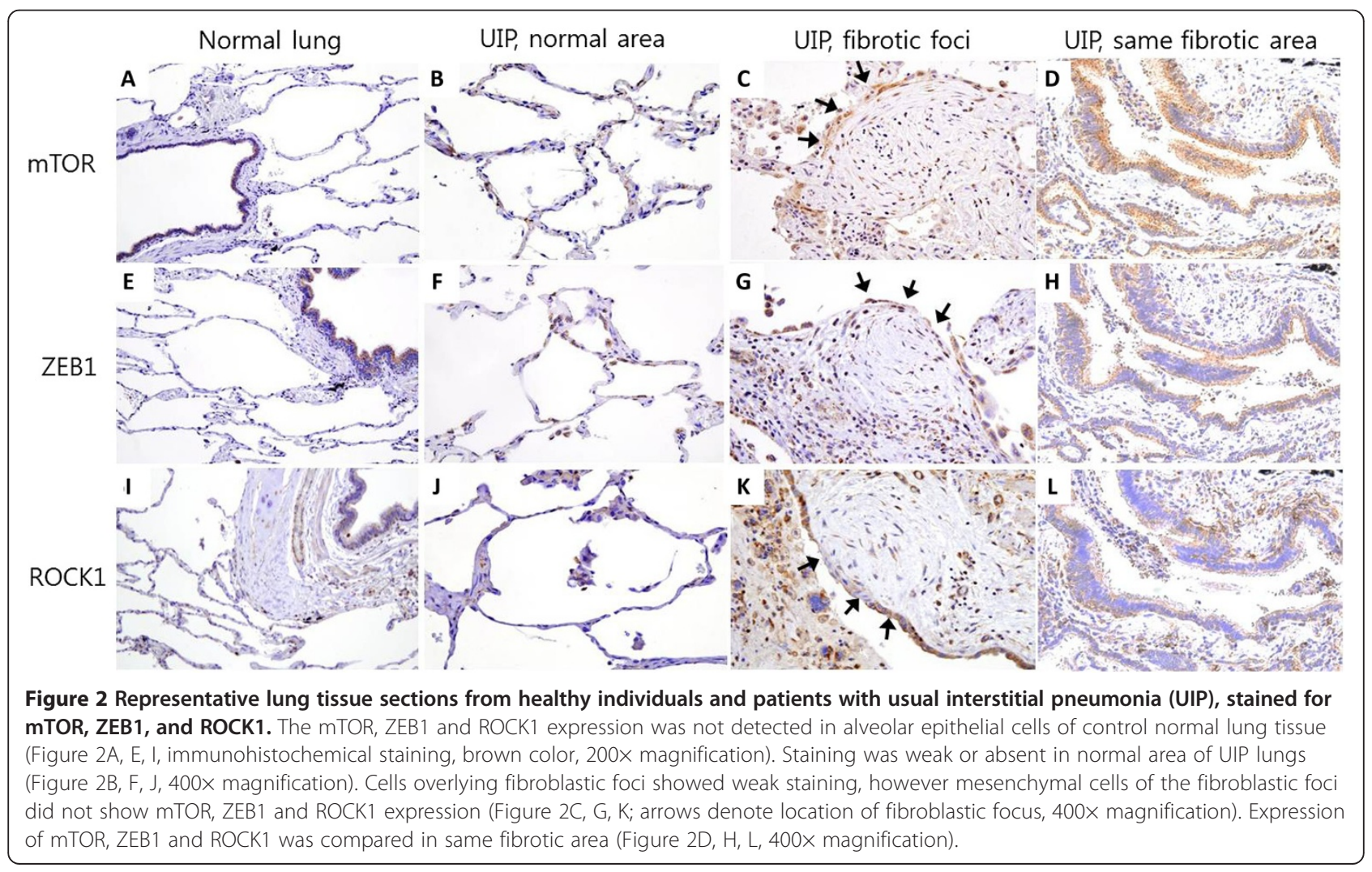


analyzed by using the Mann-Whitney Test for continuous variables and Fisher's exact test for categorical variables using SPSS 18.0 statistical software. Pearson's test was used to verify the association between fibrosis score and mTOR, ZEB1, and ROCK1 expression. A Kaplan-Meier curve was plotted for survival analysis. A p-value of $<0.05$ was considered as significant.

\section{Results}

\section{Characteristics of the study patients}

The median age of the patients was 57 years (range, 38-74 years), including 14 male patients (46.7\%; Table 1$)$. Four patients had connective tissue disease (CTD), however histologic patterns were UIP. Sixteen patients were on steroid or immunosuppressive treatment. The mean forced vital capacity (FVC) and carbon monoxide diffusion capacity $\left(\mathrm{DL}_{\mathrm{CO}}\right)$ of the patients was $75 \%$ and $65 \%$, respectively. The patient survival rate during the follow-up period (median, 40 months; range, 5-74 months) was $80 \%$ (24 patients survived). Baseline clinical characteristics were not different between the patients with IPF and CTD-ILD (Table 2).

\section{Expression of mTOR, ZEB1 and ROCK1 in the lung tissues of pulmonary fibrosis}

The mTOR and ZEB1 were mainly expressed in the hyperplastic alveolar epithelial cells and in some mesenchymal cells of UIP lungs (Figure 1C,D,E,F). The ROCK1 expression was detected in the hyperplastic alveolar epithelial cells, some mesenchymal cells, macrophages, and lymphocytes of the UIP patients (Figure 1G,H). The mTOR, ZEB1 expression was not detected in the control normal lung tissue, except in the bronchial epithelial cells (Figure 2A, E). ROCK1 expression was not detected in the normal lung tissue alveolar epithelial cells, but detected in bronchial epithelial cells and surrounding smooth muscle cells (Figure 2I). Cells overlying fibroblastic foci showed weak staining, however mesenchymal cells of the fibroblastic foci did not show mTOR, ZEB1 and ROCK1 expression (Figure 2C, G, K). Staining was weak or absent in normal area of UIP lungs (Figure 2B, F, J).

The correlation of the 3 markers with each other was evaluated (Tables 3, 4 and 5). The mTOR strong expression group showed higher ROCK1 expression scores $(\mathrm{p}=0.006)$; however, ZEB1 expression scores were not related to the mTOR scores (Table 3 ).

Clinical characteristics in relation to the expression of mTOR The strong mTOR expression group had significantly higher $(\mathrm{p}=0.034)$ histological fibrosis scores than those of the negative and intermediate expression groups (Table 3). In addition, the annual decline in $\mathrm{FVC}$ and $\mathrm{DL}_{\mathrm{CO}}$ was higher in the strong mTOR expression group than that in the negative and intermediate expression groups (Table 2).
Table 3 Clinical characteristics according to the expression of $\mathrm{mTOR}$

\begin{tabular}{|c|c|c|c|}
\hline & $\begin{array}{c}\text { mTOR negative, } \\
\text { intermediate }(n=13)\end{array}$ & $\begin{array}{c}\text { mTOR strong } \\
(n=17)\end{array}$ & $p$ value \\
\hline $\begin{array}{l}\text { Age, years, median } \\
\text { (range) }\end{array}$ & $64(38-74)$ & $57(38-70)$ & 0.714 \\
\hline Male sex & $5(38.5)$ & $9(52.9)$ & 0.484 \\
\hline Ever smoker & $4(30.8)$ & $7(41.2)$ & 0.708 \\
\hline FVC, \% & $73.0 \pm 15.2$ & $74.8 \pm 16.1$ & 0.748 \\
\hline $\mathrm{DL}_{\mathrm{CO},} \%$ & $62.1 \pm 20.3$ & $64.1 \pm 32.7$ & 0.857 \\
\hline $\mathrm{PaO}_{2}, \mathrm{mmHg}$ & $99.8 \pm 18.1$ & $86.2 \pm 11.6$ & 0.023 \\
\hline BAL Neutrophil, \% & $25.5 \pm 24.5$ & $21.3 \pm 21.9$ & 0.736 \\
\hline BAL Lymphocyte, \% & $22.5 \pm 12.9$ & $14.2 \pm 6.0$ & 0.116 \\
\hline $\begin{array}{l}\text { Radiologic } \\
\text { honeycombing score }\end{array}$ & $1.7 \pm 2.7$ & $2.4 \pm 2.6$ & 0.351 \\
\hline $\begin{array}{l}\text { Histologic fibrosis } \\
\text { score }\end{array}$ & $10.1 \pm 8.7$ & $15.0 \pm 8.1$ & 0.034 \\
\hline$\Delta \mathrm{FVC}, \mathrm{mL}$ & $109 \pm 375$ & $-151 \pm 174$ & 0.044 \\
\hline $\begin{array}{l}\Delta \mathrm{DL}_{\mathrm{CO}}, \mathrm{mL} / \mathrm{mmHg} / \\
\end{array}$ & $0.72 \pm 2.24$ & $-1.19 \pm 1.36$ & 0.023 \\
\hline$\Delta \mathrm{FVC}, \%$ & $6.7 \pm 17.1$ & $-4.4 \pm 4.9$ & 0.041 \\
\hline$\Delta \mathrm{DL}_{\mathrm{CO}}, \%$ & $5.2 \pm 12.9$ & $-5.2 \pm 6.2$ & 0.021 \\
\hline Survivors & $11(84.6)$ & $13(76.5)$ & 0.672 \\
\hline ZEB1 & $2.4 \pm 2.4$ & $3.7 \pm 2.8$ & 0.185 \\
\hline ROCK1 & $1.6 \pm 1.9$ & $4.4 \pm 2.9$ & 0.006 \\
\hline
\end{tabular}

Definitions of abbreviations: $\mathrm{BAL}=$ bronchoalveolar lavage.

$\triangle$ : change of pulmonary function per year (final minus initial pulmonary function).

Data are presented as mean \pm SD or numbers (\%) and analyzed by the Fisher's exact test or Mann-Whitney test.

$\mathrm{PaO}_{2}$ was lower in strong expression group than in the negative and intermediate expression groups $(\mathrm{p}=0.023$ ). The strong mTOR expression group had significantly higher ROCK1 expression scores than those of the negative and intermediate expression groups. The mTOR expression score significantly correlated with the fibrosis score $(r=0.441, p=0.015$; Figure $3 \mathrm{~A})$. However, mTOR expression did not correlate with the honeycombing score, FVC, and DLCO. During the study period, no fatality was observed in the mTOR-negative group. In contrast, the mTOR-positive (intermediate and strong) group had $6 \mathrm{fa}$ talities. (Figure 4A; $\mathrm{p}=0.325$ ).

\section{Clinical characteristics in relation to ZEB1 expression}

Patients with positive (intermediate and strong) ZEB1 expression showed higher fibrosis scores, greater annual rate of decline in $\mathrm{DL}_{\mathrm{CO}}$ (\% predicted), and higher mTOR scores than that of patients with negative ZEB1 expression (Table 4). The ZEB1 expression score did not significantly correlate with the fibrosis score (Figure 3B), honeycombing score, FVC, and DLCO. Similar to the findings related to mTOR lung tissue expression, no fatality 
Table 4 Clinical characteristics according to the expression of ZEB1

\begin{tabular}{|c|c|c|c|}
\hline & $\begin{array}{l}\text { ZEB1 negative } \\
(\mathrm{n}=4)\end{array}$ & $\begin{array}{l}\text { ZEB1 intermediate, } \\
\text { strong }(n=26)\end{array}$ & $p$ value \\
\hline $\begin{array}{l}\text { Age, years, median } \\
\text { (range) }\end{array}$ & $61(52-74)$ & $57(38-72)$ & 0.362 \\
\hline Male sex & $1(25.0)$ & $13(50.0)$ & 0.602 \\
\hline Ever smoker & $2(50.0)$ & $9(34.6)$ & 0.611 \\
\hline $\mathrm{FVC}, \%$ & $86.0 \pm 17.5$ & $72.2 \pm 14.7$ & 0.099 \\
\hline $\mathrm{DL}_{\mathrm{CO}}, \%$ & $61.5 \pm 19.7$ & $63.5 \pm 29.1$ & 0.892 \\
\hline $\mathrm{PaO}_{2}, \mathrm{mmHg}$ & $88.1 \pm 5.5$ & $92.7 \pm 17.1$ & 0.606 \\
\hline BAL Neutrophil, \% & $37.6 \pm 31.6$ & $19.3 \pm 19.3$ & 0.213 \\
\hline BAL Lymphocyte, \% & $13.3 \pm 5.6$ & $18.5 \pm 10.6$ & 0.433 \\
\hline $\begin{array}{l}\text { Radiologic } \\
\text { honeycombing score }\end{array}$ & $1.5 \pm 3.0$ & $2.1 \pm 2.6$ & 0.656 \\
\hline $\begin{array}{l}\text { Histologic fibrosis } \\
\text { score }\end{array}$ & $1.6 \pm 1.3$ & $14.0 \pm 8.0$ & $<0.001$ \\
\hline$\Delta \mathrm{FVC}, \mathrm{mL}$ & $105 \pm 487$ & $-47 \pm 298$ & 0.517 \\
\hline $\begin{array}{l}\Delta \mathrm{DL}_{\mathrm{CO}}, \mathrm{mL} / \mathrm{mmHg} / \\
\min \end{array}$ & $2.16 \pm 3.54$ & $-0.57 \pm 1.77$ & 0.067 \\
\hline$\Delta \mathrm{FVC}, \%$ & $4.8 \pm 17.6$ & $0.2 \pm 13.0$ & 0.647 \\
\hline$\Delta \mathrm{DL}_{\mathrm{CO}}, \%$ & $14.0 \pm 21.5$ & $-1.8 \pm 9.1$ & 0.047 \\
\hline Survivors & $4(100)$ & $20(76.9)$ & 0.557 \\
\hline mTOR & $1.5 \pm 3.0$ & $4.6 \pm 2.8$ & 0.039 \\
\hline ROCK1 & $1.3 \pm 0.9$ & $3.5 \pm 2.9$ & 0.183 \\
\hline
\end{tabular}

Definitions of abbreviations: $\mathrm{BAL}=$ bronchoalveolar lavage.

$\triangle$ : change of pulmonary function per year (final minus initial

pulmonary function).

Data are presented as mean \pm SD or numbers (\%) and analyzed by the Fisher's exact test or Mann-Whitney test.

was observed in the ZEB1-negative group (Figure 4B; $\mathrm{p}=0.326)$.

\section{Clinical characteristics in relation to ROCK1 expression}

Pulmonary function, honeycombing, and histological fibrosis scores were not different among ROCK1 negative, intermediate, and strong expression groups (Table 5). However, ROCK1 expression was associated with fibrosis score $(\mathrm{r}=0.441, \mathrm{p}=0.024$; Figure $3 \mathrm{C})$. Survival was not significantly associated with the ROCK1 expression (Figure 4C).

\section{Discussion}

This was the first study to evaluate mTOR, ZEB1, and ROCK1 expression in the lung tissues of pulmonary fibrosis patients. We evaluated the expression of mTOR, ZEB1, and ROCK1 proteins in the lung tissue, along with clinical parameters such as radiological honeycombing score, histological fibrosis score, pulmonary function, and patient survival rate. The expression of mTOR, ZEB1, and ROCK1 was increased in most of the lung tissues of pulmonary fibrosis patients. The expression of mTOR and ZEB1 significantly correlated with the fibrosis score and pulmonary
Table 5 Clinical characteristics according to the expression of ROCK1

\begin{tabular}{lccc}
\hline & $\begin{array}{c}\text { ROCK1 negative, } \\
\text { intermediate }(\mathbf{n}=\mathbf{1 6})\end{array}$ & $\begin{array}{c}\text { ROCK1 strong } \\
(\mathbf{n}=\mathbf{1 4})\end{array}$ & p value \\
\hline $\begin{array}{l}\text { Age, years, median } \\
\text { (range) }\end{array}$ & $63(39-74)$ & $55(38-72)$ & 0.110 \\
Male sex & $7(43.8)$ & $7(50.0)$ & 1.000 \\
Ever smoker & $6(37.5)$ & $5(35.7)$ & 1.000 \\
FVC, \% & $73.6 \pm 13.6$ & $74.5 \pm 17.9$ & 0.871 \\
DLCO, \% $_{\text {PaO }}$ mmHg & $58.4 \pm 21.7$ & $68.8 \pm 33.2$ & 0.332 \\
BAL Neutrophil, \% & $92.8 \pm 12.3$ & $91.1 \pm 19.9$ & 0.784 \\
BAL Lymphocyte, \% & $32.4 \pm 26.8$ & $14.7 \pm 14.3$ & 0.129 \\
Radiologic & $18.8 \pm 12.5$ & $16.3 \pm 7.6$ & 0.646 \\
honeycombing score & $1.7 \pm 2.7$ & $2.4 \pm 2.6$ & 0.496 \\
Histologic fibrosis & $10.1 \pm 8.7$ & $15.0 \pm 8.1$ & 0.123 \\
score & & & \\
$\Delta$ FVC, mL & $-20 \pm 190$ & $-45 \pm 401$ & 0.856 \\
$\Delta$ DLco, mL/mmHg/ & $-0.05 \pm 1.72$ & $-0.59 \pm 2.33$ & 0.547 \\
min & & & \\
$\Delta$ FVC, \% & $0.4 \pm 6.3$ & $0.8 \pm 17.8$ & 0.936 \\
$\Delta$ DLCO, \% & $1.0 \pm 10.3$ & $-1.9 \pm 11.9$ & 0.530 \\
Survivors & $12(75.0)$ & $12(85.7)$ & 0.657 \\
mTOR & $3.1 \pm 2.9$ & $5.4 \pm 2.7$ & 0.033 \\
ZEB1 & $2.9 \pm 2.9$ & $3.4 \pm 2.3$ & 0.361 \\
\hline Defntons of abbres & &
\end{tabular}

Definitions of abbreviations: $\mathrm{BAL}=$ bronchoalveolar lavage.

$\triangle$ : change of pulmonary function per year (final minus initial pulmonary function).

Data are presented as mean \pm SD or numbers (\%) and analyzed by the Fisher's exact test or Mann-Whitney test.

function change. During the follow-up period, there were no fatalities in the patient group with undetectable mTOR or ZEB1 expression. However, ROCK1 expression was not associated with the assessed clinicopathologic features.

In clinical settings, mTOR inhibitors are used as immunosuppressants to prevent graft rejection. Activated mTOR complex regulates cell cycle and therefore, treatment with mTOR inhibitors, such as rapamycin, leads to cell cycle arrest in the G1 phase. The key immunosuppression mechanism of mTOR inhibitors is to block clonal proliferation and expansion of stimulated lymphocytes. However, mTOR inhibitors also block proliferation of other cell types such as vascular smooth muscle cells, mesangial cells, and endothelial cells and have antifibrotic activity [12]. The anti-fibrotic effects of mTOR inhibition have been reported in various rat models of diabetic nephropathy, glomerulosclerosis, tubulointerstitial fibrosis, and liver cirrhosis [13-16]. In the murine pulmonary fibrosis model, rapamycin treatment resulted in reduced lung collagen deposition $[3,17,18]$. However, the role of mTOR in human pulmonary fibrosis has not been evaluated. 

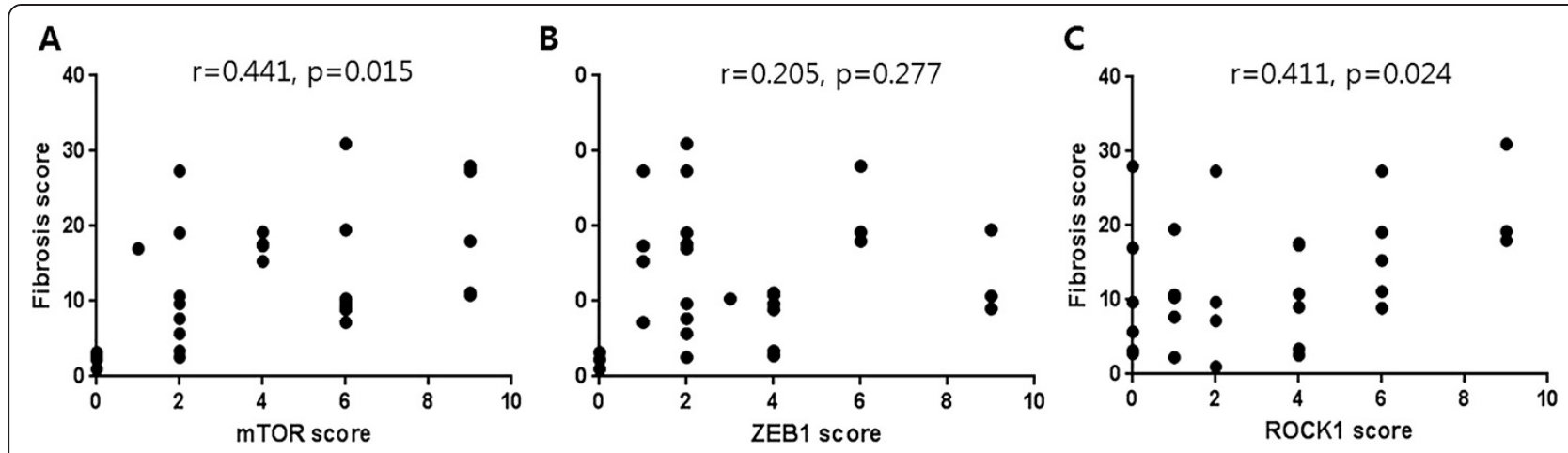

Figure 3 Association of $m$ TOR(A), ZEB1(B), and ROCK1(C) expression with fibrosis score.

In our study, expression of mTOR was increased in most of the UIP lung tissues and significantly correlated with the fibrosis score and pulmonary function change. Thus, mTOR expression may be related to the prognosis of pulmonary fibrosis. mTOR was mainly expressed in the alveolar epithelial cells of pulmonary fibrosis patients. The alveolar epithelial cells have a crucial role in pathogenesis of IPF. Repetitive microinjuries to the alveolar epithelium drive a pathogenic cascade of IPF. Activated alveolar epithelial cells stimulate fibroblasts to secrete various profibrotic cytokines [19]. mTOR expression in the alveolar epithelial cells indicates that mTOR may play a role in the pathogenesis of IPF by promoting alveolar epithelial cell proliferation. Although mesenchymal cells such as fibroblasts or myofibroblasts rarely expressed mTOR in our study, a previous study showed that an mTOR inhibitor suppressed fibroblast growth [20]. Recently, it was reported that rapamycin suppressed TGF- $\beta 1$-induced expression of collagen and fibronectin levels in primary human lung fibroblasts [21]. The role of mTOR should be further evaluated not only in fibroblasts but also in alveolar epithelial cells.
Considering the antiproliferative effect of the MTOR inhibitors [12] and expression of mTOR in UIP lungs, mTOR inhibitor may be a potential therapeutic drug for the treatment of IPF. The effectiveness of rapamycin (sirolimus) for IPF is currently under investigation in a pilot clinical trial [22].

Epithelial-mesenchymal transition (EMT) induced by TGF- $\beta$ is thought to be a potential mechanism underlying the development of pulmonary fibrosis. TGF- $\beta$ induces EMT by both Smad-dependent and Smad-independent signaling events [23]. Smad-dependent signaling upregulates the expression of several transcription factors, including Snail, Slug, Twist, and members of the ZFH family, ZEB1 and ZEB2, all of which are essential for EMT induction. These transcription factors activate EMT by binding to the E-box elements present in the E-cadherin promoter and by suppressing the synthesis of E-cadherin, a cell-cell adhesion protein [24]. A recent study revealed that the ZEB1 gene is overexpressed in the lung tissues from patients with interstitial lung disease [6]. In our study, ZEB1 was overexpressed in the alveolar epithelial cells from pulmonary fibrosis patients. Moreover, ZEB1
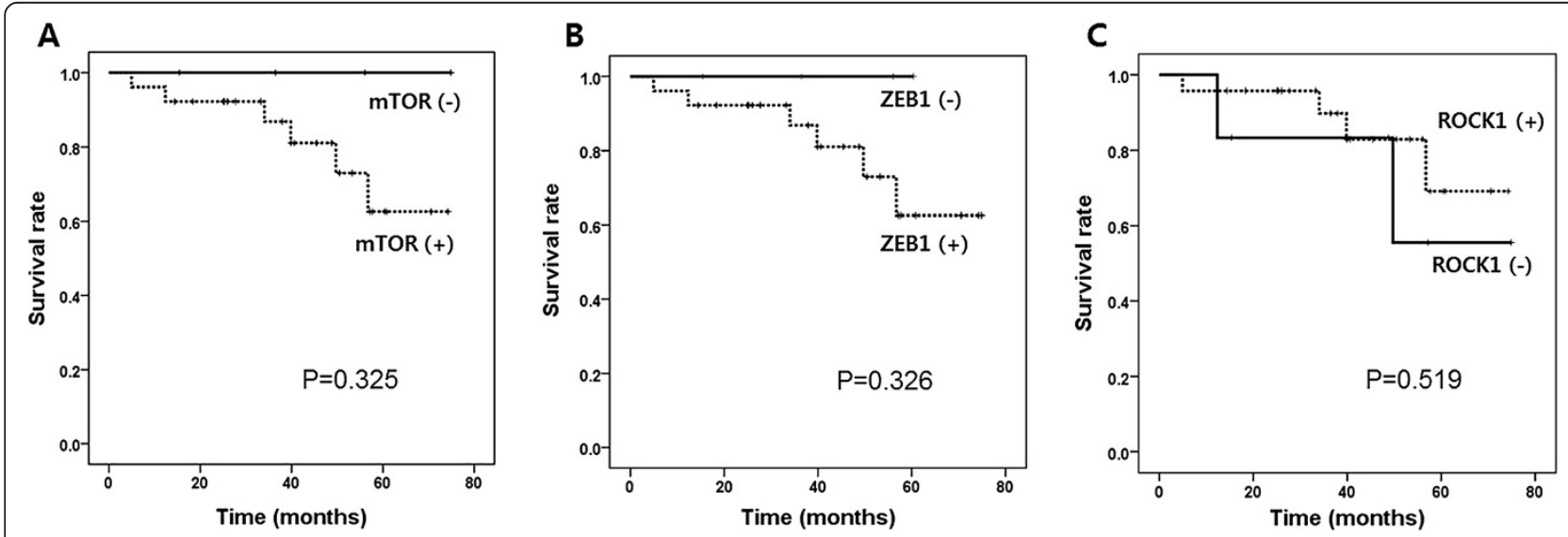

Figure 4 Patient survival in association with the expression of $m T O R(A), Z E B 1(B)$ and ROCK1(C) expression; (-) represents negative expression group and $(+)$ represents intermediate and strong expression group. 
expression was related to fibrosis score and change in $\mathrm{DL}_{\mathrm{CO}}$.

In addition to Smad pathway, multiple signaling proteins have been implicated in the TGF- $\beta$-induced EMT. ROCK is one of the proteins associated with EMT [25]. ROCK inhibitor with ZEB1/ZEB2 knockdown restored epithelial proteins from the mesenchymal state of renal tubular epithelial cells [26]. A previous study reported that treatment with ROCK inhibitor reduced the fibrosis score in a murine lung fibrosis model [7]. However, ROCK1 expression was not associated with any other clinicopathological characteristics in our study.

Further studies are required to address the findings of our data. For examples, functional studies are needed to identify the role of mTOR, ROCK1, and ZEB1 in the pathogenesis of pulmonary fibrosis. In addition, we included CTD-ILD patients that showed UIP features in lung tissue. At enrollment, these patients were diagnosed with IPF. However, the diagnosis was changed to CTD-ILD on follow-up visits due to the late presentation of CTD symptoms. It is possible that the marker expression were influenced by the inclusion of other disease types (CTD-ILD) that were not IPF. However, baseline lung function and expression scores of each marker were not different in patients with IPF and CTD-ILD. After excluding 4 patients with CTD-ILD, change of lung function decline and fibrosis scores were related to the mTOR and ZEB1 expression level (data not shown).

Furthermore, a study with a large sample size is required to evaluate whether the association of patient survival rate with the expression level of mTOR and ZEB1 is statistically significant.

\section{Conclusions}

We first demonstrated that mTOR, ZEB1 and ROCK1 was expressed in hyperplastic alveolar epithelial cells of human pulmonary fibrosis lungs. Furthermore, mTOR and ZEB1 were associated with clinical outcomes such as lung function decline. Thus, mTOR and ZEB1 expression may be related with the prognosis of pulmonary fibrosis and disease progression. Because our patients included some patients with CTD-ILD, further studies involving large numbers of homogeneous IPF patients are warranted to determine whether mTOR and ZEB1 are true prognostic markers of pulmonary fibrosis.

\section{Abbreviations}

mTOR: mammalian target of rapamycin; ROCK1: Rho-associated, coiled-coil containing protein kinase 1; UIP: Usual interstitial pneumonia; ZEB1: Zinc finger E-box-binding homeobox 1.

\section{Competing interests}

The authors declare that they have no competing interests.

\section{Authors' contributions}

JSP and YWK conducted the study, drafted the manuscript. YSP and HJP reviewed and analyzed the histology slides. SML, JJY, CGY, YWK, SKH designed this study. All authors read and approved the final manuscript.

\section{Acknowledgments}

This study was supported by a grant of Korea Healthcare Technology R\&D Project, Ministry of Health \& Welfare, Republic of Korea (A100190).

\section{Author details}

${ }^{1}$ Division of Pulmonary and Critical Care Medicine, Department of Internal Medicine, Seoul National University College of Medicine, Seoul National University Bundang Hospital, Seongnam-si, Gyeonggi-do, Korea. ${ }^{2}$ Department of Pathology, Seoul National University Bundang Hospital, Seongnam-si, Gyeonggi-do, Korea. ${ }^{3}$ Division of Pulmonary and Critical Care Medicine, Department of Internal Medicine, Seoul National University College of Medicine, Seoul National University Hospital, Medicine, 101 Daehak-ro, Jongno-gu, Seoul 110-744, Korea.

Received: 20 July 2013 Accepted: 15 October 2014

Published: 31 October 2014

\section{References}

1. King TE Jr, Pardo A, Selman M: Idiopathic pulmonary fibrosis. Lancet 2011, 378(9807):1949-1961.

2. Hartford CM, Ratain MJ: Rapamycin: something old, something new, sometimes borrowed and now renewed. Clin Pharmacol Ther 2007, 82(4):381-388.

3. Korfhagen TR, Le Cras TD, Davidson CR, Schmidt SM, Ikegami M, Whitsett JA, Hardie WD: Rapamycin prevents transforming growth factor-alphainduced pulmonary fibrosis. Am J Respir Cell Mol Biol 2009, 41(5):562-572.

4. Buschhausen L, Kamm M, Arns W, Schulze-Lohoff E, Weber M: [Successful treatment of a severe case of idiopathic pulmonary fibrosis with rapamycin]. Med Klin (Munich) 2005, 100(3):161-164.

5. Gregory PA, Bert AG, Paterson EL, Barry SC, Tsykin A, Farshid G, Vadas MA, Khew-Goodall Y, Goodall GJ: The miR-200 family and miR-205 regulate epithelial to mesenchymal transition by targeting ZEB1 and SIP1. Nat Cell Biol 2008, 10(5):593-601.

6. Cho JH, Gelinas R, Wang K, Etheridge A, Piper MG, Batte K, Dakhallah D, Price J, Bornman D, Zhang S, March C, Galas D: Systems biology of interstitial lung diseases: integration of mRNA and microRNA expression changes. BMC Med Genomics 2011, 4:8

7. Shimizu Y, Dobashi K, lizuka K, Horie T, Suzuki K, Tukagoshi H, Nakazawa T, Nakazato Y, Mori M: Contribution of small GTPase Rho and its target protein rock in a murine model of lung fibrosis. Am J Respir Crit Care Med 2001, 163(1):210-217.

8. American Thoracic Society/European Respiratory Society : American Thoracic Society/European respiratory society international multidisciplinary consensus classification of the idiopathic interstitial pneumonias. Am J Respir Crit Care Med 2002, 165(2):277-304.

9. Park YS, Park CM, Lee HJ, Goo JM, Chung DH, Lee SM, Yim JJ, Kim YW, Han SK Yoo CG: Clinical implication of protease-activated receptor-2 in idiopathic pulmonary fibrosis. Respir Med 2013, 107(2):256-262.

10. Ashcroft T, Simpson JM, Timbrell V: Simple method of estimating severity of pulmonary fibrosis on a numerical scale. J Clin Pathol 1988, 41(4):467-470.

11. Akira M, Sakatani M, Ueda E: Idiopathic pulmonary fibrosis: progression of honeycombing at thin-section CT. Radiology 1993, 189(3):687-691.

12. Sarbassov DD, Ali SM, Sabatini DM: Growing roles for the mTOR pathway. Curr Opin Cell Biol 2005, 17(6):596-603.

13. Lloberas N, Cruzado JM, Franquesa M, Herrero-Fresneda I, Torras J, Alperovich G, Rama I, Vidal A, Grinyo JM: Mammalian target of rapamycin pathway blockade slows progression of diabetic kidney disease in rats. J Am Soc Nephrol 2006, 17(5):1395-1404.

14. Wu MJ, Wen MC, Chiu YT, Chiou YY, Shu KH, Tang MJ: Rapamycin attenuates unilateral ureteral obstruction-induced renal fibrosis. Kidney Int 2006, 69(11):2029-2036.

15. Kramer S, Wang-Rosenke Y, Scholl V, Binder E, Loof T, Khadzhynov D, Kawachi H, Shimizu F, Diekmann F, Budde K, Neumayer HH, Peters H: Low-dose mTOR inhibition by rapamycin attenuates progression in anti-thy1-induced chronic glomerulosclerosis of the rat. Am J Physiol Renal Physiol 2008, 294(2):F440-449. 
16. Patsenker E, Schneider V, Ledermann M, Saegesser H, Dorn C, Hellerbrand C, Stickel F: Potent antifibrotic activity of mTOR inhibitors sirolimus and everolimus but not of cyclosporine $A$ and tacrolimus in experimental liver fibrosis. J Hepatol 2011, 55(2):388-398.

17. Mehrad B, Burdick MD, Strieter RM: Fibrocyte CXCR4 regulation as a therapeutic target in pulmonary fibrosis. Int I Biochem Cell Biol 2009, 41(8-9):1708-1718.

18. Simler NR, Howell DC, Marshall RP, Goldsack NR, Hasleton PS, Laurent GJ, Chambers RC, Egan JJ: The rapamycin analogue SDZ RAD attenuates bleomycin-induced pulmonary fibrosis in rats. Eur Respir J 2002, 19(6):1124-1127.

19. Fernandez $I E$, Eickelberg $\mathrm{O}$ : New cellular and molecular mechanisms of lung injury and fibrosis in idiopathic pulmonary fibrosis. Lancet 2012, 380(9842):680-688.

20. Nair RV, Huang X, Shorthouse R, Adams B, Brazelton T, Braun-Dullaeus R, Morris RE: Antiproliferative effect of rapamycin on growth factor-stimulated human adult lung fibroblasts in vitro may explain its superior efficacy for prevention and treatment of allograft obliterative airway disease in vivo. Transplant Proc 1997, 29(1-2):614-615.

21. Gao Y, Xu X, Ding K, Liang Y, Jiang D, Dai H: Rapamycin inhibits transforming growth factor beta1-induced fibrogenesis in primary human lung fibroblasts. Yonsei Med J 2013, 54(2):437-444.

22. Clinicaltrials.gov, A service of the U.S. National Institutes of Health. http:// clinicaltrials.gov/ct2/show/NCT01462006?term=mTOR\%2C+idiopathic +pulmonary+fibrosis\&rank=1.

23. ten Dijke P, Hill CS: New insights into TGF-beta-Smad signalling. Trends Biochem Sci 2004, 29(5):265-273.

24. Aigner K, Descovich L, Mikula M, Sultan A, Dampier B, Bonne S, van Roy F, Mikulits W, Schreiber M, Brabletz T, Sommergruber W, Schweifer N, Wernitznig A, Beug H, Foisner R, Eger A: The transcription factor ZEB1 (deltaEF1) represses Plakophilin 3 during human cancer progression. FEBS Lett 2007, 581(8):1617-1624.

25. Bhowmick NA, Ghiassi M, Bakin A, Aakre M, Lundquist CA, Engel ME, Arteaga $\mathrm{CL}$, Moses HL: Transforming growth factor-beta1 mediates epithelial to mesenchymal transdifferentiation through a RhoAdependent mechanism. Mol Biol Cell 2001, 12(1):27-36.

26. Das S, Becker BN, Hoffmann FM, Mertz JE: Complete reversal of epithelial to mesenchymal transition requires inhibition of both ZEB expression and the Rho pathway. BMC Cell Biol 2009, 10:94.

doi:10.1186/1471-2466-14-168

Cite this article as: Park et al.: Clinical significance of mTOR, ZEB1,

ROCK1 expression in lung tissues of pulmonary fibrosis patients. BMC

Pulmonary Medicine 2014 14:168.

\section{Submit your next manuscript to BioMed Central and take full advantage of:}

- Convenient online submission

- Thorough peer review

- No space constraints or color figure charges

- Immediate publication on acceptance

- Inclusion in PubMed, CAS, Scopus and Google Scholar

- Research which is freely available for redistribution 